\title{
Travel Discourses: Narrative of Witnessing Human Rights in Samanth Subramanian's This Divided Island (2014)
}

\author{
R. Samuel Gnanaraj ${ }^{1} \&$ S. Azariah Kirubakaran ${ }^{2}$ \\ ${ }^{1}$ PhD Research Scholar, Department of English, Bishop Heber College (Autonomous), \\ Tiruchirappalli (Affiliated to Bharathidasan University, Tiruchirappalli). ORCID: oooo- \\ ooo2-2837-1175.Email: rgsam93@gmail.com \\ ${ }^{2}$ Assistant Professor, Department of English, Bishop Heber College (Autonomous), \\ Tiruchirappalli (Affiliated to Bharathidasan University, Tiruchirappalli) \\ Email: sak.bhc@gmail.com
}

\begin{abstract}
Travel discourses very often reflect what the traveller encounters among the people, regarding their culture, tradition and space. The nuance of encountering the novelty is pivotal for a traveller. Samanth Subramanian in This Divided Island emancipates many restraints through identifying the solitude and unseen areas in the divided island (Sri Lanka). This paper aims to present the narrative of violation of human rights through embracing the interdisciplinary subject of travel across boundaries. Human rights and travel writing are vital to its subject. It establishes the narrative of witnesses of the internal war that happened in Sri Lanka between the Sinhalese and the Tamils for three decades. The narrative discourses in This Divided Island bear the truth of witnessing. This paper also comprises two component features. One, it establishes that travel writing witnesses the unseen realm of humanity during the wartime in Sri Lanka, and two, it witnesses the deep memories and rebuilds it. The sufferers of the war were neither majority nor minority. The important facets of the civilians who were affected internally and externally underwent a period of transition, where they became victims or they were restructured as militants. Subramanian's This Divided Island brings strength and reveals unknown factors and transmits the violated rights through narrating the events.
\end{abstract}

Keywords: Travel, Witnessing, Human Rights, Memories, Rebuilding

Travel discourses very often reflect what the traveller encounters among the people regarding their culture, tradition and space. It has always been identified as exploring the unexplored. The narratives collect and examine stories from individuals about a variety of concrete life situations on how individuals experience certain events and structure them in coherent sequences with a subjective meaning. Though travel narratives are widely explored and translated, many of them are less taken for study. The Australian columnist Luke Slattery clearly observes that, "Travel literature may be struggling to find purchase in our post-romance age, but it's worth remembering that literature begins with travel. Travel writing is not some kind of branch of literature; it's the very taproot." (Slattery, 2020). The advent of interdisciplinary scholarship always unbound any discipline and directed it to search across the boundaries. Pramod K Nayar (2009) in his article, "Affective Travel: Terror and the Human Rights Narrative in Veronique Tadjo's The Shadow of Imana" laid the platform for travel narratives and human rights by stating:

(c) AesthetixMS 2020. This Open Access article is published under a Creative Commons Attribution Non-Commercial 4.o International License (http://creativecommons.org/licenses/by-nc/4.o/), which permits non-commercial re-use, distribution, and reproduction in any medium, provided the original work is properly cited. For citation use the DOI. For commercial re-use, please contact editor@rupkatha.com. 
"human rights demand a 'narrative', and that travel literature 'is' a human rights narrative." (p. 36) He further adds, "Travel writing here is linked to human rights discourse because it constructs genocidal spaces." (p. 37) Hence, discussing human rights in a travel narrative is the inclusive part of this paper. As an emerging author and a leading journalist based in Delhi, Samanth Subramanian visited post-war Sri Lanka, met various people and revisited their lives in detail. The narratives of witnessing violation of human rights thus come out in his book This Divided Island: Stories from the Sri Lankan War (2014). This paper examines the factors based on the framework of Kay Schaffer and Sidonie Smith's Human Rights and Narrated Lives (2004) and Pramod K Nayar's Human Rights and Literature: Writing Rights (2016). Understanding the relationship of travel narratives and human rights presents constructive discourses.

Through travelling and conversing, Subramanian contributes his experience and understanding of the civil war that happened in Sri Lanka for decades. As a traveller, he investigated the things which made the island turn into a graveyard for many years. At the beginning of the book he introduces the war-torn city of Colombo as, "The streets of Colombo teemed with metal barriers and security checks; we were advised to carry our passports wherever we went." (2014, p. 17) A deep distress around the island with a tensed situation draws a frightenvisaging entry to the land. Through his meetings with the survivors he makes the shattered lives of the people during the war visible and also accounts for the ruthlessness of the war crimes and its actions.

This paper highlights travel discourse as a part of human rights witness, where the witness voices the truth and reconstructs the histories. Witness generally means one who perceives the incidents in and around the place, whereas testimony is about the spoken or written statements of the happenings. Both witness and testimony offers an insight in developing the components. The traveller's reception and his meeting with the people of the land, the culture, the tradition and space were accompanied with the empathy towards the people. In spite of many challenges during his travel, he gets into the ground work to examine the lives of the people. According to Schaffer and Smith (2004), "Stories provide necessary evidence and information about violations. They put a human face to suffering." (p. 3) Subramanian's transmission of the violence makes him a representative human rights activist in engaging with the survivors by creating a platform of discourse where the constrained life can be discussed. This article mainly comprises of two component features based on the human rights perspectives. First, it establishes how Subramanian in This Divided Island witnesses the unseen sufferings of humanity during the war, and second, how he helps to bring out the deep memories of the people and rebuild their individual lives.

The visit of Subramanian to the island is closely after the war, so he further delineates the incidents in three different aspects: pre-war, during the war and its aftermath. He records two main things in his visit: the place and the people. For many years Sri Lanka had been in an utmost terrific state. People were suffering through the fear of violence, and past memories were unfolded through witnesses. By meeting various displaced survivors, refugees, perpetrators, army men and Buddhist monks from Sri Lanka, Canada and UK, he travelled to investigate the human condition. The conversations as a travel journalist reflected the people, their culture, tradition and space. Though the writer was from India and with a Tamil background, he adapted himself in an unknown land (strange land for Tamils) to witness everything. To a Sri Lankan, both India and Tamil Nadu are undesirable. India sent Indian Peace Keeping Force (1987-1990) to Sri Lanka as an accord, which was universally recognised as a failure at the end. Many argue that after the IPKF, the war intensified. 
Adityan, a Tamil insurgent survivor in London, heeds his physical attack during the war. He disclosed to the traveller his bodily wound that happened during the attack: "He proudly yanked up his sweater to show me a curved, livid scar running from breastbone to navel." (p. 142) The war against the Sri Lankan army injured him corporeally and disclosing the wound liberated him from the fetters; he was released by the physical and emotional wounds that he had gone through. During the conflict the habitations of the civilians turn out to be the war arena. Many times war restrains the victims from moving to the next phase in their lives. The deformities that take place in human beings during the wartime place a miserable conflict in the mind and memories of the survivors. Conveying the testimonies of the victims and victors add the substances of depraved conditions of humanity.

The traveller brings out the experiences of the Tamils who worked in the government institutions during the passing of the Sinhala Only Act. They were asked to learn the spoken and written Sinhalese language for their promotions. S. Pathmanathan states, "You know, look, I had nothing against the Sinhalese,' he said. 'But I thought this policy was just plain discriminatory." (p. 57) He also claims, "Learning Sinhalese were considered as traitors by the Tamil trade union." (p. 56) He is in a state where he cannot go with any group. It affects not only the life of an individual, but also the family and the community. Dr. Thurairaja, a Tamil, retired as a major general from the Sri Lankan army in 1988 claimed his affect by the act as, "Tamil officers found it difficult to receive routine promotions." (p. 59) The incidents that happened to the people in the island were inconceivable and they have come across many burns, both, internally and externally. The civilians and refugees were devastated by the government and armed personnel. Thurairaja believed that "the civil war began partly because Sri Lankan Tamils were never allowed to rise in the government's institutions." (p. 53) The power over the land constituted a visible discrimination in dehumanizing the Tamils. "Dehumanization enabled the perpetrator to "ignore or reject the particularity of each and every person' in favour of a conceptualization." (Nayar, 2016, p. 4) The minorities were rejected by the majority and their rights trashed. The majority failed to recall that rights are always plural, a famous saying, 'I am because we are, and because we are therefore I am', “the war broke out after few years" (p. xi). This act eliminated hope and sowed the seed of fear. The war followed many assassinations of leaders; civilians were looted and shelled till the government announced a victory over the Tigers in 2009.

For many decades, division and discrimination become the keywords and Subramanian rightly claims the title of the book as This Divided Island. The island was divided mainly because it denied rights to the people. The division was among the rulers and insurgents because of political gain. The land underwent many strikes and divisions which led to high level devastation. The notion of travelling with people is indeed a certain indication and transition in witnessing the violence. The victims, refugees and the ones who escaped from the country during the violence are the only survivors of the war. Further, Subramanian conveys that travel writing is a medium that not only expresses the adoring side of the state, but also the prosaic side of the dismayed people, subjugated lives and remnants. The aftermath of the war addresses the conquest, "Sri Lanka was a country pretending that it had been suddenly scrubbed clean of violence. But it wasn't, of course." (p. 10) Though the country pretended as if nothing had happened, actually it has lost its peace. The ambiance of the land was built with violence and terror:

It never required much to begin a conversation in Sri Lanka. The very air was primed for it. In a country so full of uncertainty, all life, and all death, was rehearsed through conversation. It was a form of art, well-honed and practised with skill. (Subramanian, 2014, p. 15） 
James Dawes, a Human Rights teacher and a critic, put forth an important role of conversing as "the most important act of rescue for them is not delivering supplies but asking questions, evaluating answers, and pleading with those of us who observe from a distance." (Dawes, 2009, p.394) Schaffer and Smith also claim:

As people meet together and tell stories or read stories across cultures, they began to voice, recognize, and bear witness to a diversity of values, experiences, and a ways of imagining a just social world, and of just responding to injustice, inequality and human suffering." (Schaffer \& Smith 2004, p.1)

Subramanian describes his experience of conversing as, "Sanjaya made me realize that all I wanted to do was to wander around the island and talk about the one subject that everybody wanted to talk about." (p. 16) The people's urge of talking and discussing makes him ask questions, evaluate answers and bring up the stories by recognizing the voices of the witnesses. Survivors were asked to answer the questions and to share the incidents that happened to them. It clearly deciphers that the survivors were searching for a therapeutic relief to tell their stories to someone. The subjects here are the victims (injured bodies), and they bear witness about the unjust things that happened to them. They were desperate to share the stories to be heard across the international community. They wanted to "unburden themselves" and the only thing that they remembered was the "dates of disappearances." (p. 250)

The traveller also witnesses the panic outcome from a victim who is narrating the event: "My friend M. insisted, I should refer to him only as M. He was sure that he would fall afoul of the government in some way." (2014, p. 125) The fear that encapsulates M. addresses the whole land. The retaliation from the oppressors would be severe and it might affect the entire witness. Pramod K Nayar, in Literature and Human Rights stresses the importance of witnessing as, "Witnessing is the key process in the rebuilding of subjectivity after the confinement, torture and dehumanization." (Nayar, 2016, p.72) Witnessing rebuilds the humanity and delivers the victims, refugees, minorities and gender biased people from the inner confinement that they are struggling with. For the oppressors, Tamils and insurgents were the enemies; for the Tigers, the government, the Tamils and the Muslims were their enemies.

Subramanian emphasises on the reality of distress prevailing in Sri Lanka, how the rights and dignity of the Tamils were not maintained. Being a Tamil civilian in the island was considered as an illness and mere animals for the oppressors. Treating the people in sub- human level became their policy. Here, the agony of the oppressors is identified as infrahumanization where according to Nayar, "the human individual is reduced to a sub human or animal status." (Nayar, 2016, p. 28) It is witnessed that the conspiracy involved against the specific people was a common trait that the oppressors involved in. Subramanian saw that "(C)ars were stopped on the road and, if they were found to contain Tamils, burned without hesitation." (p. 32) The furious response by the mobs and the army had indeed put the Tamils in a helpless situation. The inflicted tortures in public places were widely prevalent in the land and could be described as a genocidal condition. Subramanian describes how the bodily integrity of a Tamil man had been violated:

I had seen a photograph that haunted me, and when I arrived in Sri Lanka, I dug around online and discovered it again. It dates from July 1983, and it show a reed-thin Tamil man, stripped naked by a mob, sitting on a stone plinth at a bus stop in a Colombo suburb." (p.32)

The trepidation found in the photograph makes one realise the situation of the people and the insurgency and how they were tortured by the majoritarian rulers. The powerless victim became a representational subject over all the inhumanity happening around the island. This further 
entitles the act of witnessing the human rights as a development of the travel discourse. He further adds the affective wound caused by the incident: "Every time I looked at it, I felt a hollow shock in the pit of my stomach at the casual cheer with which this brutality is being enacted." (p. 32) The victim is corporeally destroyed and the witness is psychologically disturbed by seeing the act of animalizing. Resolving the challenges, Subramanian builds the narrative tool by developing empathy as an essential requirement to build the humanitarian society. Empathy draws people and gives an understanding about the disaster that is happening in the society.

Subramanian clearly discerns, "in conversation about the war and the peace, rumour forms the chief currency. Everybody appears to have their own particular runnels of information, flowing from indistinct sources. Even the newspapers transmit them in the columns of political gossip." (p.13) The war mainly affects the inner realm and the outer realm of the civilians. The outer realm that deals externally with bombs, tortures, shells etc. equally occurred in the inner realm that deals internally which is identified as fear, loss, affects dignity, emotional torture and trauma. The things that happened externally can be punished before the law, but the incidents, memories and trauma cannot be addressed and it seems lawless. The narrative brings out their inner realm through the act of witnessing and storytelling.

The victims were also oppressed from speaking, "When I tried to tell them that I did not hit the police, they asked me to shut up ... When he hit my ears, I felt an electric shock pass through my body." (p. 10) Even out of these oppressions, people still give witness for regaining the denied rights. The unethical claim of the Tigers towards the civilians seems disruptive, "the Tigers tried to compel the residents of Jaffna and its outskirts - nearly half a million men, women and children - to leave the north and head south into the Vanni." (p.121) A sudden shifting of a place is quite uncommon; people were unwillingly put up in the new place in the Vanni. This forced exodus during the war time distressed the civilians towards unsettlement and disharmony. Both the Tigers and the army were in the mode of troubling the people. Life sustaining became a barrier for the civilians. It affected the livelihood of half a million people. The experience and the pain the civilians have undergone were dreadful.

The traveller met Ayathurai, a Jaffna born- breed, who shared his experience with the Tigers as an uncompromising secure but a compromising life. He stated: "because we felt safe under Tigers,'... you could leave the doors and windows of your house open and sleep peacefully ... they had some genuine ambition, and then it all went so wrong. They made their people suffer, and it was all in vain'." (p. 113). Comparably Nirmala, who also stood against the violence of the army claims, "As soon as the army set foot here, the extrajudicial killings began." (p. 137). So she preferred to control these atrocities by believing and supported the Tigers. In the same way, the traveller addresses his encounter with a guerrilla named Adityan whom he met in London. Adityan narrates his journey with the Tigers which is seemingly an emotional decision that restructured his life:

He argued with me that after the army bombed his school, he faced no real choice. 'At some point, the army was on one side of us and the Tigers were on the other side,' he said, in his low, assured voice. 'So of course I joined the Tigers.' (p. 142).

In the lives of Nirmala and Adityan, they were similar in approaching the injustice happening against the Tamils. They witness an emotional outburst happening before their eyes, they were quick in responding against the army. In later days, their lives turn upside down. Nirmala testifies, "A Tiger barged into her class, saying that three of his colleagues had been wounded in an attack on a police station, and that they needed temporary refuge." (p. 137) Her 
helping spirit breaks, she claims: "For making the tigers, a temporary stay for two weeks, later she was arrested and from prison she went directly to India and then to England." (p.138- 139) She talks about the loss of missing her home and her family that delineates an outbreak in her life by the incidents. As Khor, in her review claims the argument laid by Dawes, "What makes men into monsters?' The hope is that if we can understand how normal men become perpetrators." (p.1019). One can understand that the real enmity is found when the deeds are reciprocated. Here, as mentioned earlier, the survivor Adityan was made into a monster, a civilian was made into a perpetrator just because he met with the violence. In both the cases of Nirmala and Adityan, though they were for a cause, it ends in a catastrophe. Nirmala a civilian, became a victim and Adityan a civilian, became a restructured militant. It is necessary to understand that no militant was born as a militant, once they were civilians, later they become trained militants and they were emotionally stricken to hold the arms.

The traveller describes the loss of humanity during the war by exemplifying its dead condition and outbreak towards the fellow people. "The families of Tiger cadres often ate free or were allowed to buy food for next to nothing; others had to pay 30 rupees for a kilogram of rice that cost 17 rupees in Colombo." (p. 115) The misfortune among the Tamils was as M. claims, "there was no democracy within the Tigers. They antagonized their own brothers by killing them."(p. 140) Killing is not only about murdering someone, but also degrading a person or his livelihood. The unacquainted people were in the verge of rejection from every side; this was a disruptive way to the human kind. In other words, it was a kind of extrinsic force led by the Tigers to join in their group. The emotive nature was maintained by the Tigers over the oppressed, which fore looked the depravity of mankind. Schaffer and Smith claim the importance of a story: "A story can generate recognition, empathy, critical awareness, advocacy, and activism elsewhere that helps to empower people struggling locally to extend their campaigns for human rights." (Schaffer\& Smith, 2004, p. 31). This Divided Island as a travel narrative ensures in bringing empathy over the war-affected people through their stories. People who witness the events through the story were working for the promotion of rights.

Subramanian demonstrates human suffering by witnessing deep memories of the survivors while narrating the event. According to the APA Dictionary of Psychology, memory refers to "the ability to retain information or a representation of past experience, based on the mental processes of learning or encoding, retention across some interval of time, and retrieval or reactivation of the memory." (VandenBos, 2015, p. 636) Retaining the past experiences helps to analyse two important components: firstly, how the survivors are 'trying to forget' the incidents from their memories and secondly, how they are overcoming it through 'hope', as the process of healing. Bringing back memories of the negative things of their past life really affect the persons striving because they overcome the death many times and want to live. The incidents that happened in the victim's life during the war lead to a catastrophic end.

Subramanian exhibits the incidents through their stories and rebuilding their lives. He tells us of his meeting with Ravi in Canada:

It took me a while to work out that everything that Ravi could tell me about his experiences in Sri Lanka was necessarily of the past... 'Going back now will bring back too many memories, and it will hurt too much,' he told me.” (p. 66)

The out breaking situation of Ravi leads to a catastrophic end. The melancholic memories of his past days represent his brokenness and grief. He also elucidates that he is carrying his sufferings through his memories that cannot be retaliated. The pathetic condition of the survivor is the disabled nature in overcoming the memories. Ravi is a Tamil man who served in the Sri Lankan 
Army. He further added the assumptions the Sinhala had towards Tamils as, "the Tamils are going to take over our country, they're going to destroy it, and we have to protect Buddhism and Sinhalese people from these evil Tamil people who came from India, who don't even belong here." (p. 68). These deeply instigated thoughts led the army to exterminate Tamils from the island.

The clear structure in rebuilding the memories brings forth reconciliation. Reconciliation is an integral part in bringing back the peace. Narrating the events is closely connected towards the reconciliation. Subramanian opens up a space to the survivors to testify and to witness. Some memories are always quite deep in one's psyche. Here the traveller gets to know the heart of the father whose son ( 15 years of age) was abandoned by the Tigers. "He narrated the story staring in turn into each of our faces, as if a clue to his son's whereabouts might be inscribed in the whites of our eyes." (p. 252) Subramanian and his friend witnessed the people's longing about their lost children. The memories the witness carries was not smooth and light weighted, but was grimy dark and strayed. The witnesses were merely softened from their hardened hearts; through story telling it became a part of healing.

One of her friends, a doctor, had been recommending that she perhaps see a psychiatrist, to help dissolve some of the trauma that had calcified inside her, ...My daughters have stopped watching films entirely, because if they see someone on screen beaten or killed, they'll come crying to me, saying; 'the army would have beaten him like thus, wouldn't they?' (p. 284)

Regaining the repressed memory is itself a pain that accumulates a severe impact both physically and mentally. The state of the children seems miserable, by not knowing whether the person is alive or dead. Disappearance leaves a terrible wound within the person and it torments them whenever they see a film. A child affected by trauma is voluminously painful. These daughters symbolize every other child in the island who were affected by trauma, memories and even lost their parents during the war. It leaves an unmarking scar in their lives. Revisiting the memory hurts and fears overpower the children, and also affects their growth. Story telling is a therapeutic practice and a hope to recover from the deep wounded memories and child abuse.

In the war, Muslims were equally disturbed, both socially and politically. Though they were marginal, they were assaulted by the oppressors every time. But still, many people lived in fear, "Buddhist radicals were harassing Muslims" (p. 286), "Tigers and the Muslims grow flimsier and flimsier. ... Muslim man unknowingly wandered out of the house, he was immediately shot." (p. 172-173). Muslims were doubly folded by the armies and the insurgents. They were pushed to a place where they could not trust anybody. The basic quality of humanity is trust but it was broken. Ismail was injured by the two inches of shrapnel nestled within his left thigh that made him disabled. He escaped from many attacks and he shared his story:

There was another suffocating silence. Then the Tigers came back in and shouted:

'Everybody who isn't injured, get up. Come out and help us take the injured to the hospital.'

At this, Ismail's nephew, the six-year -old Akram, jumped up and in tears, shouted: 'I want to go home. I don't want to be here.'

The Tigers put the barrel of a gun into Akram's mouth and fires. 'He was right by my feet,' Ismail said and I couldn't do a thing to save him.' (p. 175) 
The strange depiction haunts one's memory, and recounting the incidents may be exercised towards reconciliation and forgiveness. The hope may bring healing to Ismail. The land and the people need healing, they are wounded physically, socially and mentally. Subramanian met an after-war survivor who could not go back to his village because the landmines there were still being cleared. His journey with the people reveals a radical change in broadcasting a hopeless life towards hope. The discourses of a traveller towards the people can address and create an impact in the international community through the witness and the story. These discourses have a boundless connection with the human rights for narrating the events. This Divided Island touches the lives of the people and motivates them towards reconciliation.

By celebrating the victory, oppressors leave unerased marks upon the victims. Though the aftermath of the war seems to be redemptive outwardly, the intention of the perpetrators was the same. This article examined the contribution of travel narrative to human rights, through stories and discourses. Travel literature, therefore, encourages human rights advancement through witnessing and storytelling. It brings an empathetic vision and a moralistic representation of the people who are undelivered by the memories. To conclude, the travel narrative ushers the catastrophic in reshaping the memories through evaluating and analysing the story. Through travels and conversations, Subramanian has recorded the events provided by the survivor's language in implanting the rights.

\section{References}

Dawes, J. (2009). Human Rights in Literary Studies. Human Rights Quarterly, 31(2), 394-409.

Retrieved from https://www.jstor.org/stable/20486757

Khor, L.L. (2019). Review of the book The Novel of Human Rights, by James Dawes. Human Rights Quarterly, 41(4), 1016-1020. Retrieved from doi:10.1353/hrq.2019.0057.

Nayar, P. K. (2009). Affective Travel: Terror and the Human Rights Narrative in Veronique Tadjo's

The Shadow of Imana. ICFAI University Journal of English Studies. 4(3-4). 35- 48.

---.(2016). Human Rights and Literature: Writing Rights. US: Palgrave Macmillan.

Schaffer, K,\& Smith, S. (2004). Human Rights and Narrated Lives: The Ethics of Recognition, London: Palgrave Macmillian.

Slattery, L. (2020, April 03). Transports of delight. The Weekend Australian, Travel. Retrieved from https://www.theaustralian.com

Subramanian, S. (2014). This Divided Island. India: Penguin Books.

VandenBos, G. R. \& American Psychological Association. (2015). APA Dictionary of Psychology. Washington, DC: American Psychological Association. 